\title{
Numerical Simulation of Low Energy Direct Contact Membrane Distillation
}

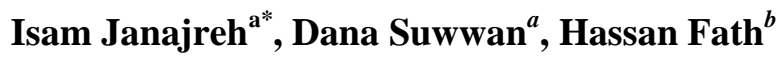 \\ ${ }^{a}$ Mechanical Engineering Program, Masdar Institute of Science \& Technology, Abu Dhabi, UAE \\ ${ }^{b}$ Environmental Engineering, Egypt-Japan University of Science and Technology (E-JUST), Alexandria, Egypt
}

\begin{abstract}
Computational Fluid Dynamics (CFD) is used to study the steady state performance of Low Energy Direct Contact Membrane Distillation (DCMD). Two-dimensional numerical model with parallel and counter flow is developed. A case of fully developed pressure driven parabolic flow is considered entering the domain at the feed and the permeate sides at $40^{\circ} \mathrm{C}$ and $25^{\circ} \mathrm{C}$, respectively. The model parameters were measured in the consideration of two dimensional fluid flow governed by the complete Navier-Stokes coupled with the energy equation for non-isothermal laminar flow. The feed stream is water at water $4 \%$ salinity, whereas the permeate stream is comprised of pure water. Across the membrane the temperature difference creates a pressure gradient responsible for the transport of vapor mass through the pours of the permeable membrane. The vapor flow is driven by two mechanisms, Knudson and Poiseuille flow. The membrane's coefficients of DCMD membrane is evaluated along with the mass flux, heat flux, and temperature polarization factor and results showed a good agreement with the published theoretical work. In view of these plausible results, parametrical study is carried out accounting for parallel and counter flow, different flow rates and inlet temperature in an attempt to achieve optimal or better yield to the Multi stage flashing method.
\end{abstract}

Keywords: Desalination, Direct Contact Membrane Distillation, Mass Transfer, Heat Transfer, Temperature Polarization

\section{Introduction}

The world's demands on potable water is on the rise triggered by human development, increase in population and the limited direct fresh water supply. This potable supply is inferior to $0.3 \%$ of what the earth has [1]. The World watch Institute vindicated that more than two-thirds of the world's population will face potable water shortage in 2025 [2]. Desalination of saline water has been the short to mid-term solution in many countries particularly in the GCC \& MENA regions.

Two different categories the desalination can be classified under, i.e. the amount of energy consumption and the energy source type. The former classification can be divided into two subcategories including conventional-energy sourced desalination and Renewable-energy sourced type [3]. The main desalination technologies include phase-change and membrane-processes. This includes several techniques such as multistage flash (MSF), multi-effect distillation (MED), vapor compression (VC), freezing, and humidification/dehumidifica-

${ }^{*}$ Corresponding author. Tel.: +971 28109130

E-mail: ijanajreh@masdar.ac.ae

(c) 2014 International Association for Sharing Knowledge and Sustainability

DOI: $10.5383 /$ ijtee.07.02.010 tion, solar stills electro-dialysis (ED), reverse osmosis (RO), and membrane distillation (MD) [1]. Many of these techniques are driven by the consumption of large amounts of fossil fuels or by using nuclear energy through co-generation. Some technologies tap on the renewable energy $[1,4]$ resources including solar or geothermal or even.

Membrane distillation is a newly emerging technology that requires low grade energy consumption compared to other technologies such as MSF or RO [5]. The benefits of membrane technology in the desalination processes lies in the fact that it provides continuous separation, as well as the ease of combining the membrane process with thermal separation processes (hybrid strategies). Also, membrane process can be modular and flexible for scale up keeping the advantage that the separation is occurring under mild conditions [1]. Another benefit lies in variable membrane properties which can be adjusted. A review on designing of membrane distillation can be found elsewhere [6,7] which include direct contact membrane distillation (DCMD), air gap membrane distillation (AGMD), vacuum membrane distillation (VMD), and sweeping gas membrane distillation (SGMD). 
DCMD is a well-known water production application that provides separation process and purification technique. The anatomy of the DCMD consists of two-flows with different temperatures and species that are separated by hydrophobic membrane, which is directly connected to the flows. The feed flow is the flow with higher temperature than the permeate flow. The temperature difference between the two flows cross the membrane surface creates a difference in the potential vapor partial pressure. This difference drives the transport of vapor mass and energy transfer from the feed side to the permeate side [6]. The advantages of the DCMD lies in its simplicity and in utilized low grade temperature difference and the potential of reaching near $100 \%$ rejection of dissolved solids [8].

Several Models of DCMD were proposed; Modeling DCMD usually falls into three main areas: macroscopic modeling, microscopic modeling, and membrane modeling. These models aim at determining the vapor's the transported mass and its resistance across the membrane. It is attributed to the membrane characteristics such as thickness, porosity, and pore size and its tortuosity. Also, these models focus on the heat transfer resistance to determine the mean temperature of the membrane surface. Most of the conducted research has selected macroscopic models to predict water productivity [9, 10, 11]. Experimental works were used for model validation along with membrane-based parameters correlation (i.e. membrane coefficient) and system-based parameters (i.e. vapor pressure difference). Comprehensive parametrical study of the different membrane parameters as well as system conditions is not present at this time. This work aims to obtain a fundamental understanding of the DCMD setup and its pronounced parameters through high fidelity flow simulation and sensitivity study. DCMD's pure water productivity has been presented in several macroscopic models. Several imperial and semi-imperial models were also proposed [1]. Lately, a model that includes the temperature polarization for a flat DCMD was proposed, this model was helpful in understanding the trans-membrane flux mechanism. Despite that, a study for DCMD in a counter flows (feed \& permeate) configuration and with the inclusion of the effect of mass flow is still lacking.

In this paper, the trans-membrane flux mechanism for the DCMD was studied utilizing high fidelity CFD analysis. Initially a baseline paralleled flow model is created followed with counter flows under different feed flow inlet temperature and flow rate flow conditions.

\section{Mathematical Model}

Schematics of the studied DCMD is illustrated in figure 1. An aqueous hot feed (Hot channel) enters the top side of the membrane while the permeate enters the bottom side of the membrane (cold channel). Evaporation and condensation of the transported pure water molecules occur at the liquid -vapor interfaces formed at pore entrance on the feed and permeate side, respectively [6]. The performance of the DCMD depends on the temperature of the feed/permeate flows, pressures and membrane characteristics.

For the modeling purposes, it was assumed that the model is two-dimensional following the Cartesian coordinates along the $\mathrm{x}$ and perpendicular to $\mathrm{y}$ directions, as illustrated in Fig 1. In the entrance region, the channel height (y-direction) is assumed to be an order of magnitude smaller than the channel length ( $\mathrm{x}$ direction). The velocity profiles are considered for the fully developed laminar flow (parabolic profile) steady and non- isothermal. The feed stream consists of a mixture of two miscible brine solution, while the permeate stream is represented by single species of fresh water.

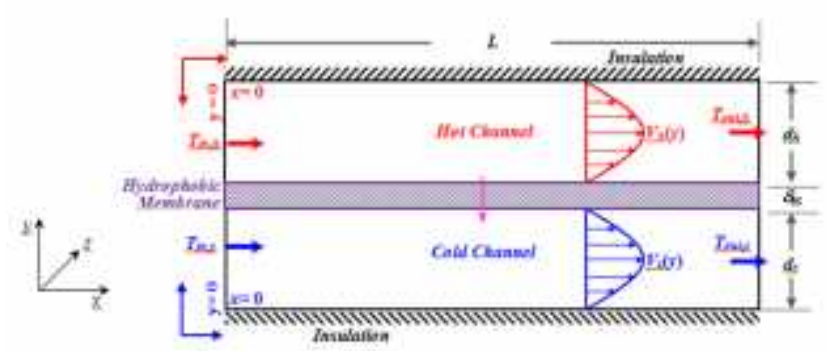

Figure 1: Schematic diagram of parallel-flow DCMD

\subsection{Governing Equations}

For the consideration flow, the countiuty equation (1) and monentuin equations in $\mathrm{x}(2)$ and $\mathrm{y}(3)$ directions are applied:

$\frac{\partial \rho}{\partial t}+\frac{\partial(p u)}{\partial x}+\frac{\partial(p v)}{\partial y}=0$

$\frac{\partial(\rho \mathrm{u})}{\partial \mathrm{t}}+\mathrm{u} \frac{\partial(\mathrm{pu})}{\partial \mathrm{x}}+\mathrm{v} \frac{\partial(\mathrm{pu})}{\partial \mathrm{y}}=-\frac{\partial \mathrm{p}}{\partial \mathrm{x}}+\mu\left(\frac{\partial^{2} \mathrm{u}}{\partial \mathrm{x}^{2}}+\frac{\partial^{2} \mathrm{v}}{\partial y^{2}}\right)$

$\frac{\partial(\rho \mathrm{v})}{\partial \mathrm{t}}+\mathrm{u} \frac{\partial(\mathrm{pv})}{\partial \mathrm{x}}+\mathrm{v} \frac{\partial(\mathrm{pv})}{\partial \mathrm{y}}=-\frac{\partial \mathrm{p}}{\partial \mathrm{y}}+\mu\left(\frac{\partial^{ \pm} v}{\partial \mathrm{x}^{2}}+\frac{\partial^{2} v}{\partial \mathrm{y}^{2}}\right)$

Where $\rho, \mathrm{u}, \mathrm{v}, \mathrm{P} \mu$ are the density, velocity in $\mathrm{x}$, velocity in $\mathrm{y}$, pressure and dynamic viscosity, respectively. As the folow is considered to be non-isothermal, the energy oquation (4) is applied.

$C_{p}\left(\frac{\partial(\rho T)}{\partial t}+u \frac{\partial(\rho T)}{\partial x}+v \frac{\partial(\rho T)}{\partial y}\right)=k\left(\frac{\partial^{2} \mathrm{r}}{\partial x^{2}}+\frac{\partial^{2} \mathrm{~T}}{\partial y^{2}}\right)$

Where $C_{p}, k, T$ are specific heat,thermal conductivity, and temperature, respectively. For tlo feed fluid with multispecies, the species transport equation (5) is applied.

$\frac{\partial C}{\partial t}+u \frac{\partial C}{\partial x}+v \frac{\partial C}{\partial y}=D\left(\frac{\partial^{2} C}{\partial x^{2}}+\frac{\partial^{2} C}{\partial y^{2}}\right)$

Where C, D are specie concentration and its diffusion coefficient. Based on the assumption of steady state flow, all differentiations with respect to time in the equations above can be eliminated or kept while seeking a time independent solution.

\subsection{Mass Flux Equations}

In the DCMD process, evaluating the transport of mass constitute the process productivity. Due the temperature gradient, a driving pressure force is created which responsible for the mass tranfer across the membrane [1]. The general form of the pass flux is illustrited by Chen and Greenlee $[4,6]$ which is written as:

$\mathrm{J}^{\prime \prime}=\mathrm{c}_{\mathrm{m}}\left(\mathrm{P}_{\mathrm{f}}^{\text {sat }}-\mathrm{P}_{\mathrm{p}}^{\text {sat }}\right)$

Where $c_{m}, P_{f}^{\text {sat }}, P_{p}^{\text {sat }}$ are the membrane coefficient, and saturated pressure of water on the feed and permeate membrane's surface, respectively. These pressures can be 
derived from the pure water vapor pressure using Antoine equation [6]:

$\mathrm{P}_{\mathrm{i} \text { (pure) }}^{\text {sat }}(\mathrm{T})=\exp \left(23.1964-\frac{3816.44}{\mathrm{~T}-46.13}\right), \mathrm{i} \in\{\mathrm{f}, \mathrm{p}\}$

And is adjusted for non-pure (saline) water as [6]:

$P_{i}^{s i t}(x, T)=x_{w} a_{w} P_{i(\text { pure })}^{\text {sat }}, i \in\{f, p\}$

Where $\mathrm{x}_{\mathrm{w}}, \mathrm{a}_{\mathrm{w}}$ are the mole fraction of the water in saline solution, and the water activity in $\mathrm{NaCl}$ solutions, respectively. The temperature is expressed in Kelvin degree (K), and the pressures is given in Pascals $(\mathrm{Pa})$. The water activity in $\mathrm{NaCl}$ solutions is estimated using the correlation equation of Khayet, [6] and Lowson [8] and is givtn as:

$\mathrm{a}_{\mathrm{w}}=1-0.5 \mathrm{x}_{\mathrm{NaCl}}-10 \mathrm{x}_{\mathrm{NaCl}}^{2}$

Where $\mathrm{x}_{\mathrm{NaCl}}$ is the mole fraction of $\mathrm{NaCl}$ in the brine solution.

Determining a mathematical model of the membrane coefficient $c_{m}$ lays its importance due to its direct effect on the mass flux. Three main models for the membrane coefficient were considered. The Knudson diffusion model, Poiseuille flow model, and molecular diffusion model. In a single gas system, the vapor molecule motions, the mean free path and pore diameter render the distinguishing between the three models. Knudson model describes the molecule-wall collisions, which become more important with larger mean path. If the pore size is larger than the mean path, Poiseuille flow model is used to describe the molecule motion due to the pressure gradient [4]. As soon as mass transfer takes place in the membrane, the diffusion mechanism in the membrane is affected by the three models simultaneously. A suitable combination between Knudson and Poiseuille models was presented by Chen et al. [4] for model verification, and investigated by Schofield et al [12]. This semi-empirical model is described as the following:

$$
\begin{aligned}
c_{m} & =c_{k}+c_{p} \\
& =1.064 \alpha(T) \frac{\tau r}{\tau \delta_{m}} \sqrt{\frac{M_{w}}{R T_{m t}}}+0.125 \beta(T) \frac{\tau T^{2}}{\tau \delta_{m}}
\end{aligned}
$$

Where $\alpha(T)$, and $\beta(T)$ are Knudsen diffusion Inodel and Poiseuille flow model contributions, respectively, $\mathrm{M}_{w}$ is the molar mass of the water in $(\mathrm{kg} / \mathrm{mol}), \mathrm{T}_{\mathrm{mt}}$ is the thean membrane temperature $(\mathrm{C}), \mathrm{R}$ is the gas constant, $\mathrm{P}_{\mathrm{m}}$ is the mean pressure, $\delta_{m}$ is the thickness of the membrane, $\eta_{v}$ is the gas vicosity, $\mathrm{r}$ is the pores radius, $\varepsilon$ is tphe porosity of the membrane, $\tau$ is the tortuosity factor, which can be estimated for hydrophobic membrane by Iversen et al. [13] such as:

$$
\tau=\frac{1}{\varepsilon}
$$

\subsection{Heat Flux Equations}

The heat transfer in DCMD process can be described following three steps: The heat transfer through the feed boundary layer, heat transfer through membrane, and heat transfer through the permeate boundary layer. The total heat flux through the membrane is due to the conduction across the melnbrane material additional to its gas-filled pores $\left(Q_{c}\right)$, and also the latent heat associated with the vaporized molecules $\left(Q_{V}\right)$. The total membrane heat flux can be described as the following:

$$
Q_{m}=Q_{c}+Q_{v}
$$

The heat transfer due to the mass transfer is described as

$$
\mathrm{Q}_{\mathrm{v}}=\mathrm{J}^{\prime \prime} \Delta \mathrm{H}=\mathrm{J}^{\prime \prime}\left(\mathrm{H}_{\mathrm{m}, \mathrm{f}}-\mathrm{H}_{\mathrm{m}, \mathrm{p}}\right)
$$

Where $\Delta \mathrm{H}$ is the difference in enthalpies between the hot (feed) and cold (permeate) sides of the membrane. The enthalpies of water vapor and liquid can be determined from the equations fitted from the enthalpy data of saturated water vapor and liquid taken from the thermodynamic property table or from the following fitted equation that applies between 273$373^{\circ} \mathrm{K}[14]$ :

$$
\mathrm{H}_{\mathrm{m}, \mathrm{i}}=1.7535 \mathrm{~T}_{\mathrm{m}, \mathrm{i}}+2024.3, \quad \mathrm{i} \in\{\mathrm{f}, \mathrm{p}\}
$$

Assuming a linear temperature distribution between $\mathrm{T}_{\mathrm{m} f \mathrm{f}}$ and $\mathrm{T}_{\mathrm{mp}}$, the conduction heat transfer through membrane is given by the following [6]:

$$
\mathrm{Q}_{\mathrm{c}}=-\frac{k_{\mathrm{m}}}{\delta_{\mathrm{m}}}\left(\mathrm{T}_{\mathrm{m}, \mathrm{f}}-\mathrm{T}_{\mathrm{m}, \mathrm{p}}\right)
$$

Where $\mathrm{k}_{\mathrm{m}}$ is the membrane thermal conductivity, which can be determined using the following combined and void weighted formula [6]:

$$
\mathrm{k}_{\mathrm{m}}=\varepsilon \mathrm{k}_{\mathrm{g}}+(1-\varepsilon) \mathrm{k}_{\mathrm{b}}
$$

Where $k_{\mathrm{b}}$ is the thermal conductivity of the membrane material, and $\mathrm{k}_{\mathrm{g}}$ is the thermal conductivity of the gas filling the membrane pores. $\mathrm{k}_{\mathrm{g}}$ can be estimated using the following formula [1]:

$$
\begin{aligned}
& \mathrm{k}_{\mathrm{g}}\left(\mathrm{T}_{\mathrm{m}}\right)=0.0144-2.16 \times 10^{-5}\left(\mathrm{~T}_{\mathrm{m}}+273.15\right)+1.32 \times \\
& 10^{-7}\left(\mathrm{~T}_{\mathrm{m}}+273.15\right)^{2}
\end{aligned}
$$

Where $\mathrm{T}_{\mathrm{m}}$ is the membrane's mean temperature.

It is known that the DCMD efficiency is limited by the heat transfer through the boundary layers [6]. In order to define and quantify the boundary layer resistance over the total heat transfer resistance, the temperature polarization $(\theta)$ is introduced and is written as:

$$
\theta=\frac{T_{m, r}-T_{m, p}}{T_{b, j}-T_{b p p}}
$$

Where $\mathrm{m}, \mathrm{b}, \mathrm{f}, \mathrm{p}$ are signify the membrane, the bulk, the feed flow and permeate flow, respectively. In ideal case $\theta$ is unity. When $\theta$ is less than 0.2 , the DCMD process is heat transfer limited and module design is poor. But if $\theta$ exceeds 0.6 , the DCMD process become mass transfer limited with low membrane permeability [6].

\section{Computational Model}

A two-dimensional Computational Fluid Dynamic (CFD) model of two channels is presented, with two fully developed flow velocity inlets, two pressure outlets. The selected domain and dimensions follow the work of Chen and Ho [1]. For the parallel flows, both feed and permeate channels flow from left to right whereas in the counter flow case the feed remains to flow the same while the permeate flows from right to left. The two domains are thermally coupled by the membrane's conductivity. In a typical parallel flow, it is expected that the 
mean temperature of the membrane remains constant. This intern substantiates a fixed and uniform conductivity for the membrane volume; whereas in counter flow the conductivity needs to be asscrted. Fig. 2 illustrates the variations in the values of $\mathrm{k}_{\mathrm{g}}$ along the length due to the change in the mean temperature $\left(\mathrm{T}_{\mathrm{m}}\right)$ according $\mathrm{tG}$ equation (17), which is directly affecting the dissipated heat flux. The variation in the trend is nearly $4 \%$ peak to peak of $\mathrm{k}_{\mathrm{g}}$. However, $\mathrm{k}_{\mathrm{b}}$ is more dominant value (nearly one order of magnitude larger) and hence $\mathrm{k}_{\mathrm{g}}$ variations brings slight change in overall heat flux and as well as in the mass flux.

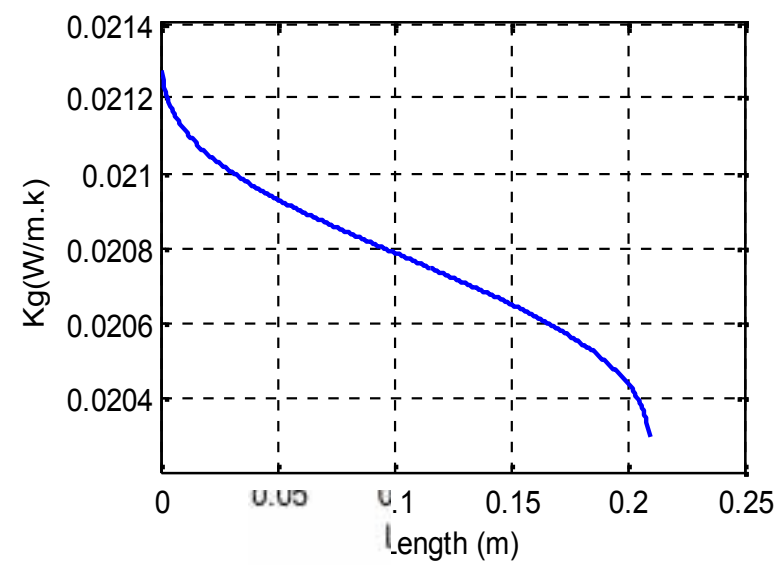

Fig. 2: Variation of $k_{n}$ across the membrane's length

Several flow velocities were selected to determine its effect on the mass flux, heat flux and the membrane performance. Also, several temperature values are selected for the feed flow inlet in order to study the change in driving force of mass flow. It is worth mentioning that an upwind $2^{\text {nd }}$ order discretization is implemented for the advective term and $2^{\text {nd }}$ order central for the diffusion following an iterative scheme.

\section{RESULTS \& Discussion}

The presented mathematical and CFD models are applied to determine the mass flux, heat flux, temperature polarization, and membrane coefficient. Table 1 summarizes the selected parameters for the model.

The temperature profile is noticed to be slightly affected by the flow velocity as depicted in fig 3 . It shows that tripling the inlet velocity value will lead to slightly higher temperature difference across the membrane that continues until the flow exit. This is due to the shorter resistance time for the flow to cool down at the feed side, or to heat up at the permeate side. These results are in agreement with those obtained by Chen [4]. It is worth mentioning that the mean temperature is almost constant for the parallel flow in the DCMD model at the three velocity values.

For counter flows, the temperature profiles gives the same trend to the change in velocities, on the other hand, the mean temperature is not fixed and it decreases along the channel length as depicted in fig 4 .

\begin{tabular}{|c|c|c|}
\hline Parameter & Symbol (unit) & Value \\
\hline Length & $\mathrm{L}(\mathrm{m})$ & 0.21 \\
\hline $\begin{array}{c}\text { Knudson \& Poiseuille f. } \\
\text { model }\end{array}$ & $\alpha(\mathrm{T}), \beta(\mathrm{T})$ & 1 \\
\hline Molar Weight & $\mathrm{M}=(\mathrm{kg} / \mathrm{mol})$ & 0.018 \\
\hline Membrane Thickness & $\delta-(\mu \mathrm{m})$ & 130 \\
\hline Gas Constant & $\mathrm{R}(\mathrm{J} / \mathrm{mol} . \mathrm{K})$ & 8.3143 \\
\hline Pores Radius & $\mathrm{r}(\mathrm{nm})$ & 50 \\
\hline Gas Viscosity & $\eta-(\mathrm{Ns} / \mathrm{m}=$ & $9.29 \mathrm{e}-6$ \\
\hline Porosity & $\varepsilon$ & 0.7 \\
\hline $\begin{array}{l}\text { Membrane Thermal } \\
\text { Conduct. }\end{array}$ & $\left.\mathrm{k}_{\mathrm{p}(\mathrm{v}} \mathrm{V} / \mathrm{mK}\right)$ & 0.178 \\
\hline
\end{tabular}

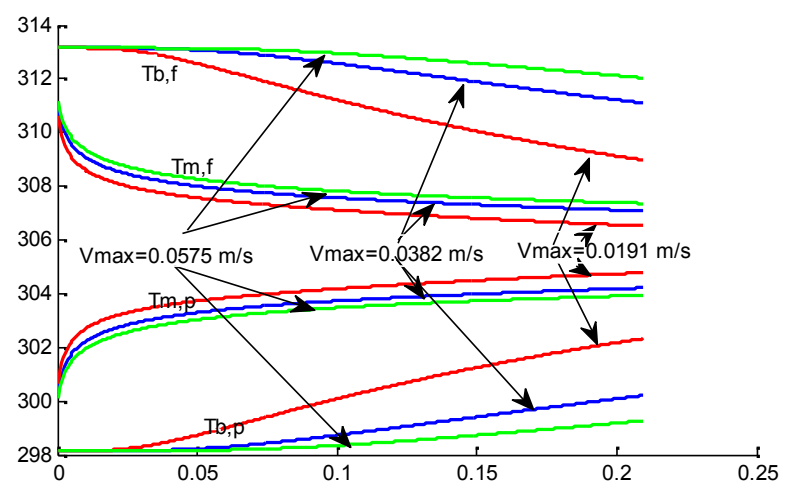

Fig. 3: Temperature profiles correspond to diffirent velocities for parallel flow (Feed: $40^{\circ} \mathrm{C}$, Permeate: $25^{\circ} \mathrm{C}$ )

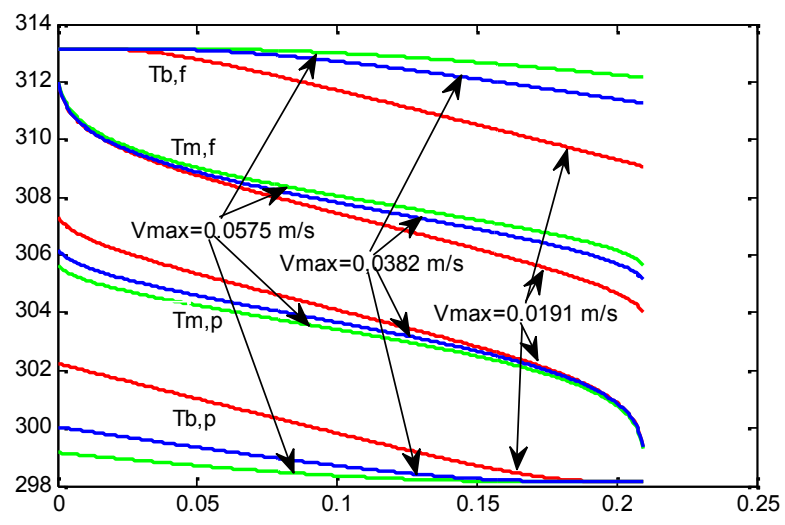

Fig. 4: Temperature profiles correspond to diffirent velocities for counter flow (Feed: $40^{\circ} \mathrm{C}$, Permeate: $25^{\circ} \mathrm{C}$ )

The mass flux, heat flux, and temperature polarization were determined for parallel flow model and counter flow model, corresponding to three feed inlet temperatures $\left(40^{\circ} \mathrm{C}, 60^{\circ} \mathrm{C}\right.$, $\left.80^{\circ} \mathrm{C}\right)$ and three flow velocities $(\mathrm{V} \max =0.0191 \mathrm{~m} / \mathrm{s}, 0.0382 \mathrm{~m} / \mathrm{s}$, $0.0575 \mathrm{~m} / \mathrm{s}$ ). The velocities were selected in accordance of maintaining a laminar flow regime.

Both models have shown that the mass flux and heat flux are directly affected by the incremental increase of temperature and velocity as depicted in fig 5 through fig 8 . In particular, the counter flow model resulted in a higher mass flux and heat flux values than the parallel flow model.

The temperature polarization shows that the parallel flow models have the tendency to exceeded the 0.6 limit at the entry 
whereas the counter flow remains within the plausible heat and mass transfer limits; beyond the relatively short upstream entry regions the two models are well-posed. The temperature polarization factor was not affected by the change of feed inlet temperature, as depicted in fig 9 , however a noticeable change was observed when flow velocity is increased. The temperature polarization factor of the counter flow model has a higher value than the parallel flow model which indicates better performance as depicted in fig 9 and fig 10 .

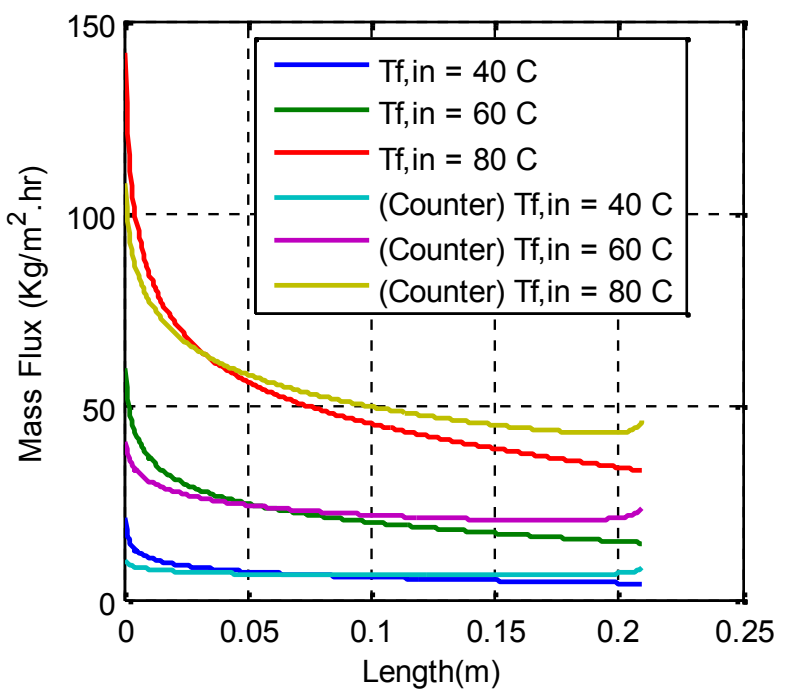

Fig. 5: Mass Flux for both flow models for several feed inlet temp.

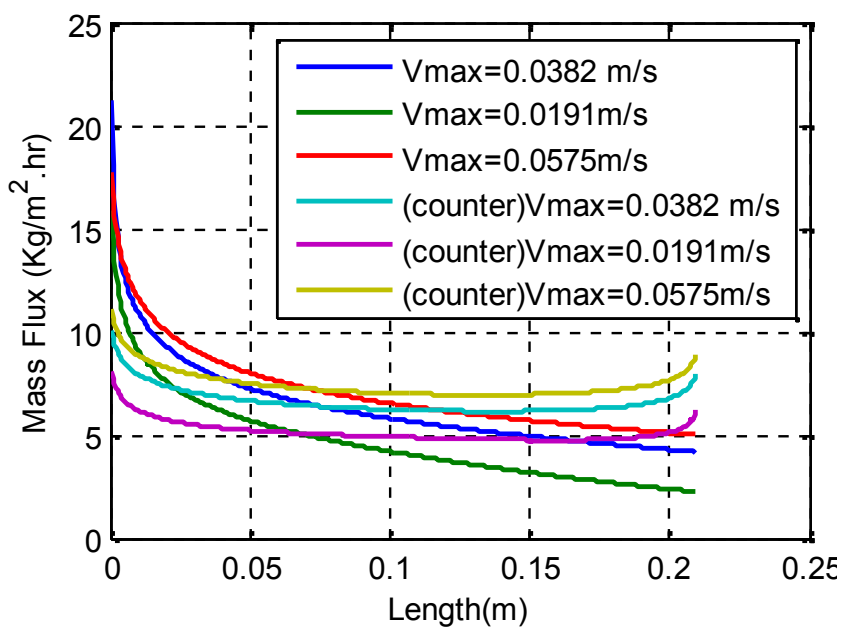

Fig. 6: Mass Flux for both flow models for several flow velocities

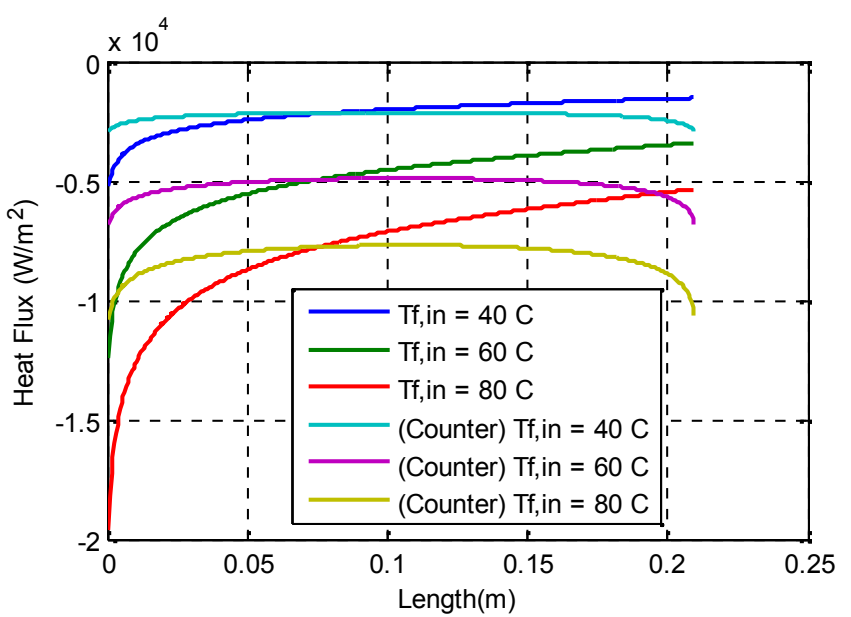

Fig. 7: Heat Flux for both flow models for several feed inlet temperatures

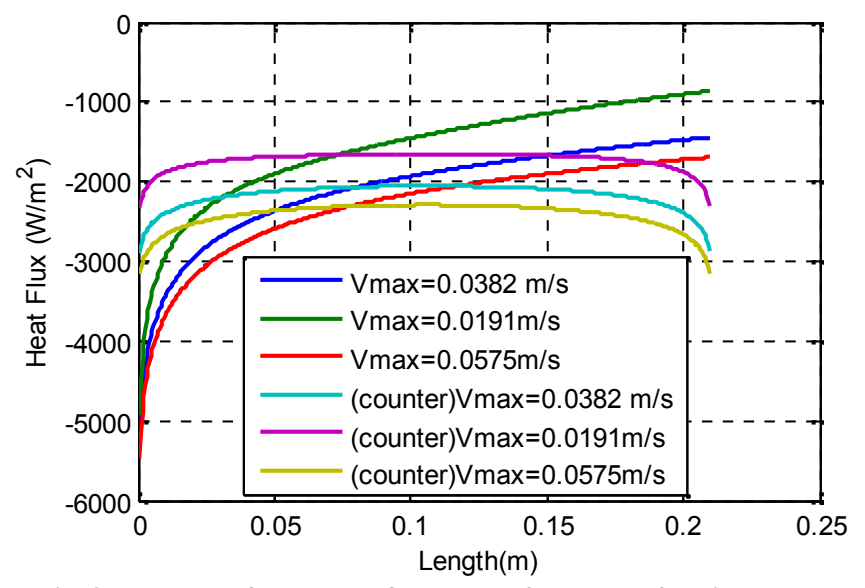

Fig. 8: Heat Flux for parallel flow model for several feed inlet temp.

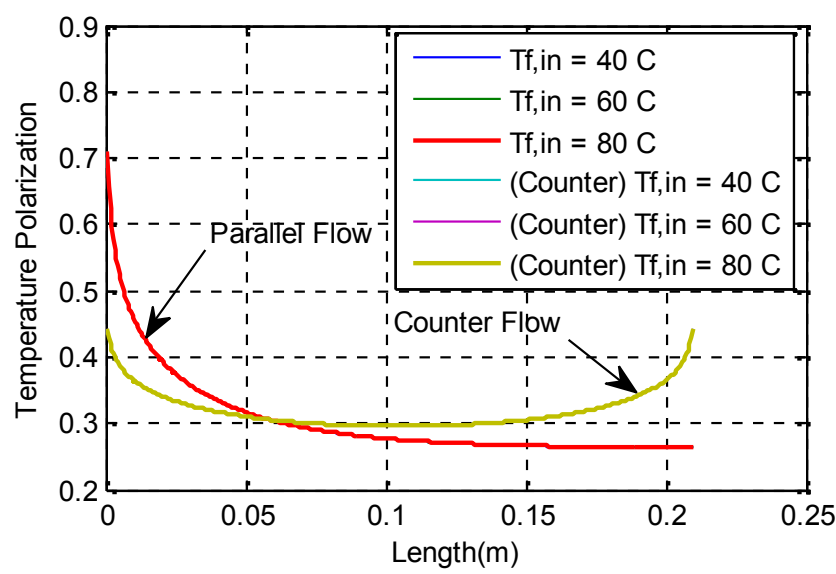

Fig. 9: Temp. Polarization for both models with multi feed inlet tem 


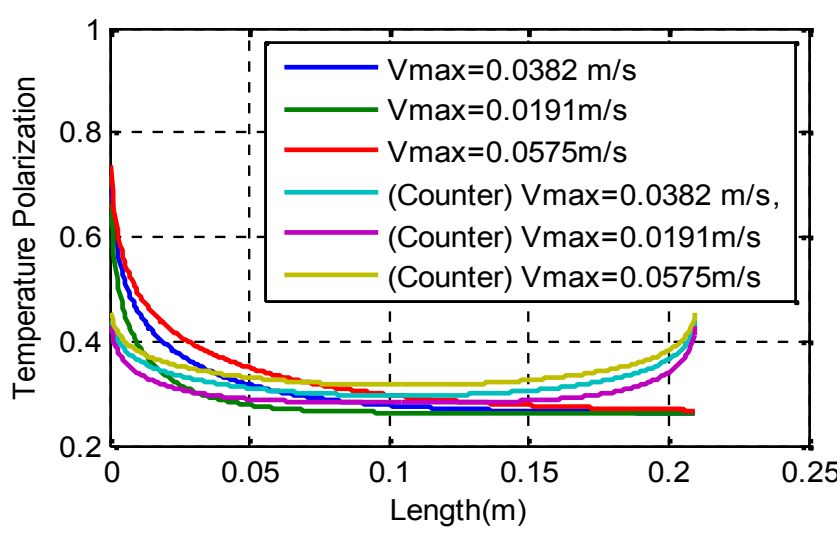

Fig. 10: Temp Polarization for both models with multi feed inlet temp

In order to get a quantitative comparison, the power per liter generation was found for both the DCMD set up using the data highlighted in the table below and the MSF was adopted from literature.

$\begin{array}{lll}\text { Values at } \mathrm{T}_{\text {avg }} & \begin{array}{l}\text { Brine-feed } \\ \text { channel }\end{array} & \begin{array}{l}\text { Fresh-cold } \\ \text { channel }\end{array} \\ \text { Density }\left(\mathrm{kg} / \mathrm{m}^{3}\right) & 1014 & 996 \\ \text { Heat Capacity (J/kg.K) } & 3200 & 1000 \\ \text { Temperatures (K) } & 40 & 25\end{array}$

The power produced per liter of fresh water is $15 \mathrm{kw} / \mathrm{Liter}$ compared to $13.3 \mathrm{kw} /$ Liter for MSF. The DCMD can be optimized further to compete with the MSF by tuning simple membrane parameters.

\section{Conclusions}

The Computational Fluid Dynamics was applied to determine a high fidelity analysis for the DCMD. The model returns the bulk temperatures and membrane temperatures for the feed flow and the permeate flow. The temperature gradient across the membrane creates a difference in the saturation pressure across the membrane fluid, which drives mass and energy transfer through the membrane from the feed to the permeate side. Analyzing the mass flux for both flow models (parallel flow and counter flow) shows that the mass flux is directly proportional to the increment of temperature difference between feed and permeate flow. This is explained by the higher difference in the pressure which in turns drives more mass transfer from feed to permeate flows. Additionally, the increase in the inlet flow resulted in a higher values of mass flux, for both flow configurations. The higher mass flux for the counter flow model indicates that it's better to use counter flow DCMD for desalination applications. The study of the heat flux has shown that it is proportionally related to the temperature difference between feed and permeate flow and the flow velocity. The heat flux for the parallel flow has shown to be less pronounced than the counter flow model. Temperature polarization was also investigated and beyond the entry region neither heat nor mass transfer limitation occurs as the TP values remains within the allotted values $\{0.2,0.6\}$.

\section{Acknowledgments}

The authors are grateful for the financial support from MASDAR Institute of Science \& Technology and for all Waste to Energy Lab to their support throughout this research.

\section{References}

[1] T. Chen , C. Ho. "Immediate assisted solar direct contact membrane distillation in saline water desalination", Journal of Membrane Science 358, pp. 122-130, 2010

[2] E. Close, E. Sorensen. "Modeling of Direct Contact Membrane Distillation for Desalination" ESCAPE20, 2010.

[3] H.M. Ettouney, H.T. El-Dessouky, R.S. Faibish, P.J. Gowin, "Evaluating the economics of desalination", Chem. Eng. Prog. 98 pp. 32-39, 2002.

[4] T. Chen, C. Ho, H. Yeh "Theoretical modeling and experimental analysis of direct contact membrane distillation", Journal of Membrane Science 330, pp. 297 287, 2009.

[5] L.F. Greenlee, D.F. Lawler, B.D. Freeman, B. Marrot, P. Moulin, "Reverse osmosis desalination: water sources, technology, and today's challenges", Water Res. 43 pp. 2317-2348, 2009.

[6] M. Khayet, T. Matsuura "Membrane Distillation, Principles and Applications" ELSEVEIER, 2011

[7] M.C. de Andrés, J. Doria, M. Khayet, L. Pe na, J.I. Mengual, "Coupling of a membrane distillation module to a multieffect distiller for pure water production" Desalination 115 pp. 71-81, 1998.

[8] K.W. Lawson, D.R. Lloyd, Membrane distillation. II. Direct contact MD, Journal of Membr.Science 120 pp. 123-133 1996.

[9] J. Phattaranawik, R. Jiraratananon, A.G Fane, "Heat transport and membrane distillation coefficients in direct contact membrane distillation" Journal of Membrane Science 212, pp. 177-193, 2003.

[10] R.W. Schofield, A.G. Fane, C.J.D. Fell, "Heat and mass transfer in membrane distillation", J. Membr. Sci. 33 pp.299-313.1987

[11] S. Srisurichan, R. Jiraratananon, A.G. Fane, Mass transfer mechanisms and transport resistances in direct contact membrane distillation process, J. Membr. Sci. 277, pp.186-194. 2006

[12] R.W. Schofield, A.G. Fane, C.J.D. Fell, "Gas and vapor transport through microporous membranes. I. KnudsenPoiseuille transition", Journal of Membrane Science 53, pp. 279-294, 1990

[13] S.B. Iversen, V.K. Bhatia, K. Dam-Jphasen, G. Jonsson, "Characterization of microporous membranes for use in membrane contactors", Journal of Membrane Science. 130, pp. 205-217, 1997.

[14] P. Termpiyakul,. R. Jiraratananon, S. Srisurichan , "Heat and mass transfer characteristics of a direct contactmembrane distillation process for desalination", Desalination 177, pp. 133-141, 2009. 